IJM

42,5

904

Received 24 August 2020

Revised 15 October 2020

Accepted 15 October 2020

\section{Migration and comparative advantages: new evidence on the EU-MENA region}

\author{
Anna Maria Ferragina and Stefano Iandolo \\ Department of Economics and Statistics, University of Salerno, Fisciano, Italy, and \\ Erol Taymaz \\ Middle East Technical University, Ankara, Turkey
}

\begin{abstract}
Purpose - This study aims to consider how migrants may act as channel of diffusion of knowledge which contributes to the dynamics of trade and comparative advantages of EU and MENA countries for the period 1990-2015.

Design/methodology/approach - Adopting an IV approach and a gravity framework to instrument for migration, the authors document how variations in stocks of migrants coming from (in) countries that are already competitive exporters of a given product impact on the probability that the destination (home) country starts to export competitively new products or succeed in exporting more intensively.

Findings - Controlling for potential confounding factors which can be correlated to knowledge flows and productivity shifts, the authors find trade-promoting effects via migration flows (mostly immigration) between the two areas, testing our hypotheses by different technology classes of products and different specifications. Originality/value - The contribution of this work to the literature is threefold. First, by providing evidence on international knowledge diffusion induced by migration flows between MENA and EU regions, like no other work before, the authors document the effects of migration on trade and comparative advantages. Second, unlike standard literature on migration-trade link, the authors focus more on long-term structural changes in comparative advantages than on trade volumes. Third, we exploit how the effect of migration on margins of trade varies according to different types of goods, classified by technological level.
\end{abstract}

Keywords Trade-migration link, Panel data approach, Trade, Extensive and intensive margin Paper type Research paper

\section{Introduction}

In the present era of international mass migration, observed in the last two decades, the US and many European countries have experienced continuous waves of immigrants, leading to structural changes in population and workforce composition.

These phenomena have given rise to a new interest in the economics of migration to look beyond the short-term effects of migration on the labour market, by exploring longer-term,

\section{JEL Classification - F14, F22, L14}

(C) Anna Maria Ferragina, Stefano Iandolo and Erol Taymaz. Published by Emerald Publishing Limited. This article is published under the Creative Commons Attribution (CC BY 4.0) licence. Anyone may reproduce, distribute, translate and create derivative works of this article (for both commercial and non-commercial purposes), subject to full attribution to the original publication and authors. The full terms of this licence may be seen at http://creativecommons.org/licences/by/4.0/legalcode

The authors would like to thank Frédéric Docquier and all the participants to the Femise 2019 conference in Brussels, 13-14 June 2019 for very helpful comments and fruitful discussions. The paper also benefited from insightful comments from Raffaello Bronzini, the participants to the SIE 2019 meeting in Palermo, and Sergio Destefanis, Giuseppe Russo and other seminar participants at DISES (University of Salerno). We would also like to thank an anonymous reviewer for very useful comments and suggestions, which substantially improved this paper, and the Research Report on which it was based carried out under the 4th round of FEMISE RESEARCH PROGRAMME on "Support to economic research, studies and dialogue of the Euro-Mediterranean Partnership". We are very grateful to Femise and to the Commission for the financial support received under the contract FEM44-11 related to ENPI/2014/354-494.
International Journal of Manpowe Vol. 42 No. 5, 2021 pp. $904-934$ Emerald Publishing Limited 0143-7720

DOI 10.1108/IJM-08-2020-0395 
dynamic effects. Among these, international trade scholars have widely documented the positive correlation between migration and trade, finding that migrants can stimulate international trade both in amount (Rauch, 1999; Aleksynska and Peri, 2014) and in ways that extend the product set of their home and host country (Peri and Requena-Silvente, 2010; Bahar and Rapoport, 2018). The economic literature, in particular, focused on how migration networks and diasporas are associated with large exports and imports towards the country of origin, as a result of connections to business networks or preferences effects (see comprehensive surveys by Rauch, 2001; Parsons and Winters, 2014; Lissoni, 2018).

In our analysis, we aim to consider how migrants' bilateral flows between EU and MENA (Middle East and North Africa) [1] may produce knowledge and information transmission which may contribute to the dynamics of world trade and comparative advantages of both MENA and EU region.

Based on the literature on international knowledge diffusion (e.g. Coe and Helpman, 1995; Keller, 2004; Aldieri et al., 2020) and on international factor flows and productivity (e.g. Kerr and Kerr, 2018), indeed, a recent stream of studies documents how at world level migrants, through the supply of specific skills and competences, can serve as natural drivers of knowledge diffusion [2] inducing productivity shifts that can be part of a convergence process in comparative advantages among countries (Bahar et al., 2014; Bahar and Rapoport, 2018).

In line with this approach, the idea behind our analysis is to test whether knowledge transmission channels seen in relation to migration flows (in addition to FDI and trade flows) can explain changes in comparative advantages in EU and MENA countries associated with migration (in and out), as measured by the ability of countries to start to export competitively products, or to export more intensively already exported products, that are also intensively exported by the migrants' home/destination countries. This channel of transfer has never been investigated before in this geographical context.

The mechanisms behind this process are that migrants (e.g. from MENA) bring information about the know-how of origin countries and the destination countries (EU) start to export goods that are produced in the country of origin of migrants. The opposite channel is also at work: migrants (from EU) observe technological processes in the destination countries (MENA) and they channel-back information to the origin countries (EU) that start to specialize in the products already produced (and exported) in countries of destination (MENA). In the end, if countries start to specialize in exporting goods not exported before, this mechanism implies convergence in the comparative advantages.

To test our hypotheses, we use changes in the export composition (i.e. the extensive margin of trade, henceforth EM) and value (i.e. the intensive margin, IM) of a country's export basket as proxies to track knowledge diffusion and cross-country productivity spillovers.

Our concept of extensive margin is based on the construction of product-level export related variables will allow us to measure the gain in a country's of a new RCA in a given product, and also to implement a procedure that enables to select migrants in (or from) countries that have a RCA greater than 1 , at product level.

Moreover, we control for product-specific factors that could induce an increase in exports, but that are not related to knowledge diffusion (e.g. global demand factors, network or preference effects).

To implement our analysis, we compile different available data sources that include bilateral data on migration, FDI, detailed (4-digit SITC) trade data, and distance and cultural data. The final dataset covers the period 1990-2015. To properly investigate the effect of migration between MENA and EU on the trade of both the areas, we split the sample into two different datasets: one covering trade of EU-27 countries with their trade partner countries, and the other covering trade relationships of 20 MENA countries.

The empirical analysis aims to solve possible identification problems which might affect our results and addresses endogeneity issues. In our specifications, indeed, there are several 
IJM

42,5

906 aspects that may influence the impact of migration on trade, not related to the diffusion of knowledge or information, that we control for.

First, the migrants from a country that is exporter of a given product might choose, based on $a$ priori knowledge, to migrate towards countries where this sector is growing. Second, changes in aggregate preferences or due to some country-specific characteristics could induce both migration and an increase in exports. Hence, a problem of endogeneity could affect our results. For this reason, we control for these potential confounders by including product-year and country-year fixed effects. In addition to this, we adopt an instrumental variable (IV) approach, instrumenting migration stocks with figures estimated by a gravity model based on common cultural and historical characteristics for sending and receiving countries. To provide an exogenous variation in the number of migrants, in line with a rich literature (e.g. Ortega and Peri, 2014; Alesina et al., 2016; Bahar and Rapoport, 2018), we estimate a Poisson pseudo maximum likelihood gravity regression to compute the predicted migration stocks following a methodology similar to Frankel and Romer (1999) by including historical and cultural characteristics.

Our paper contributes to the related literature in different ways. First, and most importantly, to our knowledge, there is no previous analysis of how and whether migrant flows between countries in the MENA and EU region do induce a change in comparative advantages both in the destination country and back to their origin countries, providing evidence of international knowledge diffusion induced by migration flows between them. The aim is providing new evidence on neglected issues of this important North-South corridor of migration, in order to generate more evidence informing the EU Trade and Migration Common Policies, as well as the EU Neighbouring Policy.

Second, while the standard literature explores the migration-trade link as referred to trade volumes, we ask, in line with a recent literature (Peri and Requena-Silvente, 2010; Bahar and Rapoport, 2018), whether migration affects the extensive margin of trade, or hinges on the intensity of exports of the basket of products already exported, that is we focus on the long-term of structural changes of the comparative advantage, by excluding small changes of trade volumes.

Third, we also see whether the effect of migration on margins of trade varies according to different types of goods, classified by technological level. This allows us to identify how knowledge intensity of the goods traded is related to the transmission of know-how through migration, given that trade in technology goods can be considered as a proxy correlated to the information and knowledge endowment of migrants and to their ability to transfer it.

Our main findings can be summarized as follows. In the benchmark estimates, we find a positive impact of immigration on exports of the host country that is statistically and economically significant while for emigrants the results are not robust. Second, the export creation effects seem to operate mainly via increases in the IM, whereas the effect on the EM is nil or even negative (in the case of the MENA region).

We check whether these results hold to a robustness check based on repeating the analysis excluding exports to those countries where migrants are in, or they are from, to rule out network and preferences effects.

The structure of the paper is as follows. In section 2 we review the main contributions of the related literature. In section 3 we describe the data and outline the empirical strategy and the theoretical framework. In section 4, we present the benchmark empirical results of the estimation strategies. In section 5 we refine the analysis carrying out some robustness checks. Finally, section 6 concludes and suggests policy implications derived from our findings. There is also an Appendix that accompanies the paper.

\section{Review of the literature}

The dominant and large strand of the literature which analyses the relationship between migration and trade, follows the pioneering works by Gould (1994), as well as early contributions of Head and Ries (1998), Rauch (1999), and Rauch and Trindade (2002). 
The following literature built the explanation of the pro-trade effect of migrations mainly on two channels (Rapoport, 2016). The first identifies the positive effect of migration on trade through a "preference" mechanism: immigrants keep their preference for some type of products from the home country. Therefore, this effect, also called "transplanted home bias" effect by White (2007), results in an increase of imports of host countries. The second channel affects both import and export flows is defined as the "network" or the "information bridge" channel [3]. In this case, the presence of migrants in a country enhance creation of networks that can promote new business opportunities by the reduction of transaction trade costs (i.e. improving information channels, or promoting business opportunities by mitigating institutional failures in business relationships) (Rauch, 2001; Wagner et al., 2002; Briant et al., 2009).

Previous studies have pointed out the effect of immigrants arriving to EU from MENA countries focusing on the role of business networks and preference channels that migration can activate. Especially Southern EU-countries (and in particular Italy, Spain, France and Portugal) have shown clear trade creation effects of people's flows via migrant networks and proximity [4]. In some studies, the observed effect is due to the network channel (Peridy, 2012; Artal-Tur et al., 2012, 2014; Cağatay et al., 2014), and in other immigrant preferences for native country goods are the key factors driving the migration-trade link (Foad, 2010).

The evidence provided so far on the EU-MENA region focuses on bilateral exports and imports also taking proximity of migrants into account and emphasising the relevance of the territories distance (in terms of geography, culture, income per capita or institutions), as relevant for bigger trade creation effects (Artal-Tur et al., 2012, 2014), and highlights the impact of migration on increasing product diversification measured by industry-level employment and number of enterprises (Cağatay et al., 2014). A recent literature has also taken into account the skill level of migrants and shown how high skilled migrants enhance the quality of exports in the frame of the network and preference effects (Giovannetti and Lanati, 2017; Giovannetti et al., 2019). Moreover, while finding the existence of a sizeable, unexploited trade potential between both groups of partners (Pastore et al., 2009), related literature, does not provide evidence on the convergence in trade which can be achieved between EU and MENA via migration.

Our study explores this path of analysis by studying another possible trade creating channel of migration and looks at the role of migrants as a vehicle to enhance convergence in terms of trade specialisation following the literature on international knowledge diffusion (Coe and Helpman, 1995 Jaffe et al., 1993; Keller, 2004; Bottazzi and Peri, 2003; Kerr, 2008) and on international factor flows and productivity (e.g. Coe and Helpman, 1995; Javorcik, 2004; Coe et al., 2009; Andersen and Dalgaard, 2011; Kerr and Kerr, 2018). Traditionally, one of the main concerns about the international migration was the so-called "brain drain" (Beine et al., 2001; Docquier and Rapoport, 2012); however, this recent literature has found positive spillovers and incentive-creating effects of migration by creating business opportunities as well as by favouring the circulation and diffusion of knowledge. Mayr and Peri (2009), with a special look at return migration, and Andersen and Dalgaard (2011) show that the intensity of temporary movements of workers is a very good predictor of global productivity levels. Lodigiani (2008) also shows that an increase in (high-skilled) emigration rates is associated with an increase in productivity back home.

The most common way to measure knowledge diffusion has been to consider patent and inventor data (specifically patent citation) (Agrawal et al., 2011; Naghavi and Strozzi, 2015; Kerr and Kerr, 2018; Miguélez, 2018). More recently, another way to track knowledge diffusion has been to look at the evolution of the export basket of countries identified as a useful proxy to measure it (Bahar et al., 2014; Bahar and Rapoport, 2018; Valette, 2018).

Bahar and Rapoport (2018) test the hypothesis of knowledge diffusion through international migration with an analysis at the product level, finding that people
EU-MENA: migration and comparative advantages

907 
IJM

42,5

908

movements can explain industry-specific productivity shifts being part of the process through which countries gain comparative advantage.

Valette (2018) considers whether international migrants contribute to increasing technological advances in developing countries by inducing a transfer of productive knowledge from developed countries back to migrants' home countries.

Our paper in the vein of these later contributions also tries to track knowledge diffusion by looking at the evolution of the intensive and extensive margin of trade of the EU and MENA countries as a result of their migration transfers.

\section{Data and estimation methodology}

The international migration literature has been traditionally producing mostly theoretical contributions due to the lack of data. More recently, however, new data have spurred a series of analyses that explore connections between stocks of migrants and economic performance. Our interest in the effect of people flows between the MENA region and the EU arises from the relevance they played in the last decades on the social, political and economic dynamics on both sides of the Mediterranean in response to regional and global geopolitical trends.

The corridor between EU and countries bordering the Mediterranean, indeed, has been one of the most important. More than 18 million people born in the Southern basin of Mediterranean are living in 2018 in EU countries. The reasons are different (e.g. geographical nearness, dissimilar level of wealth and employment opportunities), as well as the potential sociological and economic implications (Artal-Tur et al., 2014).

Almost one out of four migrants from MENA arrives to Europe (6.4 million equals to $24.1 \%$ in 2015) (UN, 2017). Despite the increasing flows from Eastern Europe after 1990, and from many developing countries in Africa, immigrants from MENA still represent the most important source of migration from non-developed countries to EU with around $14 \%$ of total immigrants flows to EU and the same sizeable shares as in 1990.

For our purposes we consider different publicly available data sources that include bilateral data on migration and trade (see Table A2 in Appendix).

For migration, we use the data from the United Nations (Trends in International Migrant Stock: The, 2015 revision). UN dataset provides data on bilateral migration stocks for a195*195 matrix of origin-destination combinations, for the years: 1990, 1995, 2000, 2005, 2010, 2015 [5].

In Tables 1 and 2 we describe migration shares for EU28 and for MENA. If we look at the share of immigrants to EU, the MENA region has been a key and growing source area of migrants in the past years, although East European countries and developed countries have always played a dominant role as source of migrants (Table 1).

People's outflows from MENA region are strongly directed towards other MENA countries, but also to developed countries, France, Turkey and USA being priority destinations. There are strong historical linkages between some EU countries and especially Northern African countries. The main people's flows arriving to the EU region were from Morocco, Algeria and Tunisia, with immigrants mainly establishing in Spain, France, Italy and Germany.

Migrants moving from one MENA country to another (intra-regional flows) mainly establish in Palestine, Syrian Arab Republic and Egypt.

Concerning trade, we use product data from the UN COMTRADE for the period 19902015, with products classified according to the Standard Industry Trade Classification (SITC) (Rev. 2) [6] with a four-digit level of detail.

Moreover, we use the data by Head and Mayer (2014) provided by the Centre d'étudesprospectives et d'informationsinternationales (CEPII) for distance and cultural data (the dataset provides information on colony-coloniser relationship, and common language, 


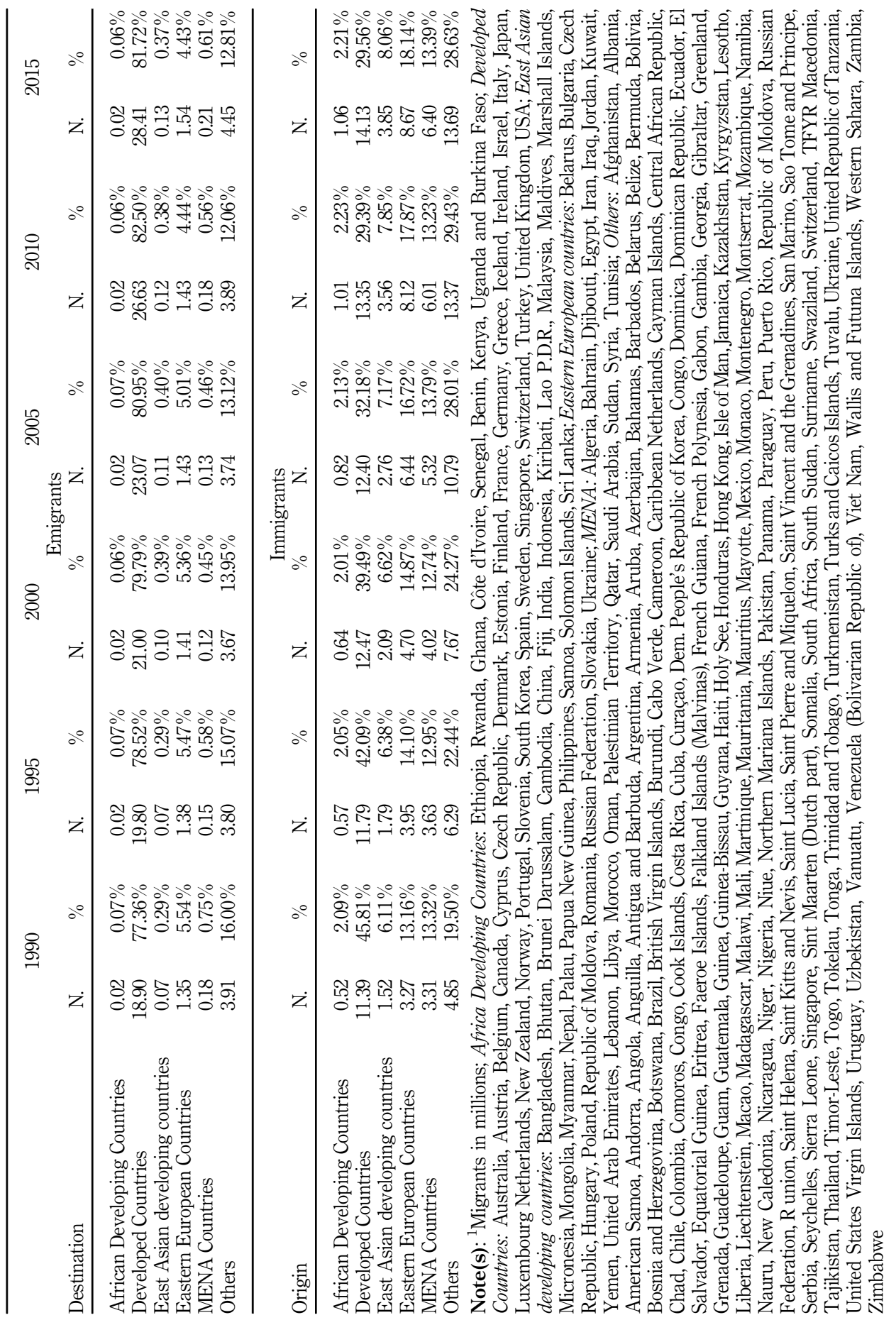

EU-MENA: migration and comparative advantages

909

Table 1.

EU 28 migration partners $^{1}$ 


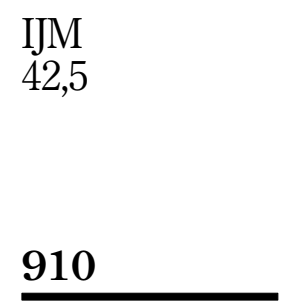

Table 2.

MENA migration partners

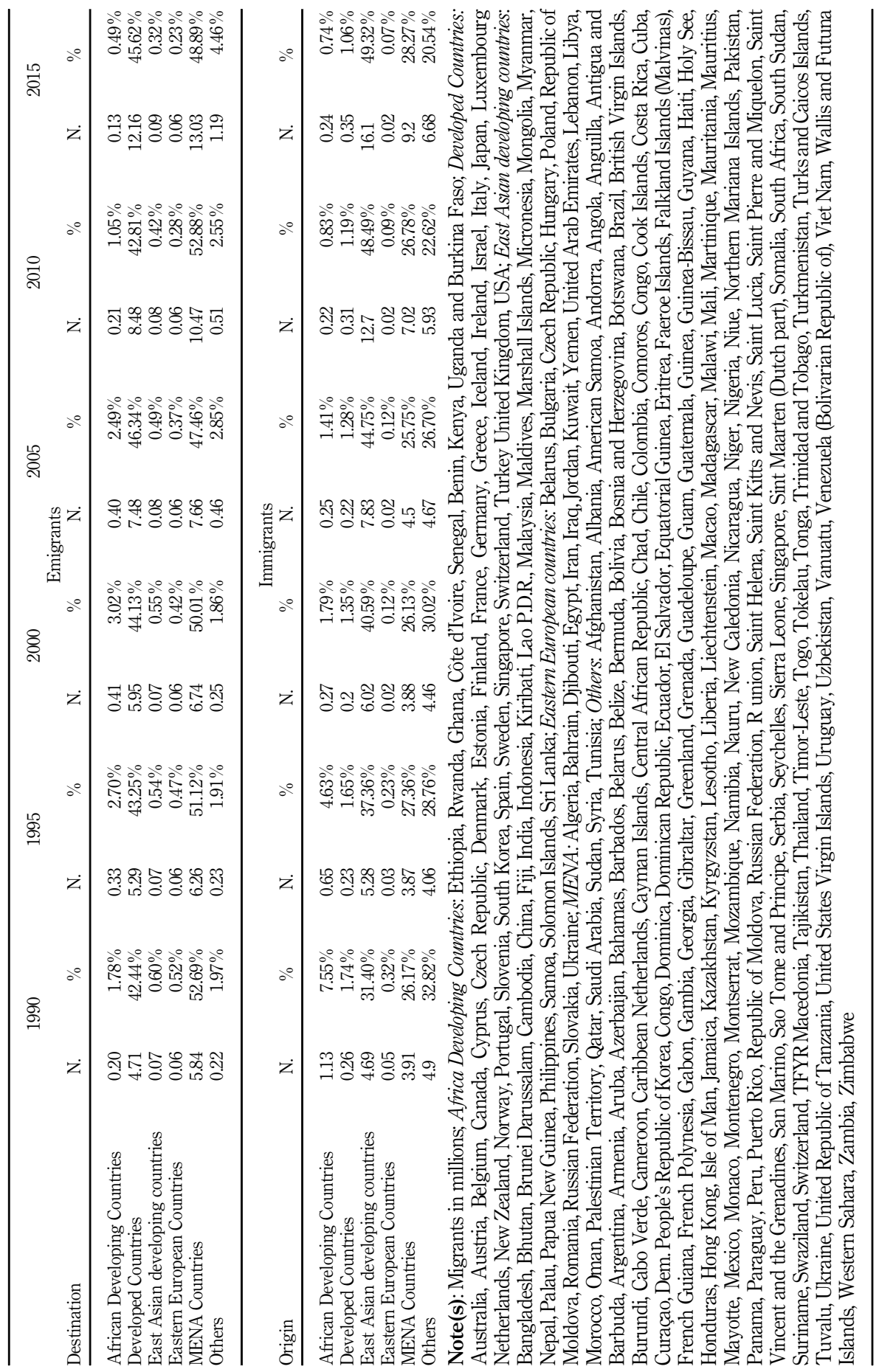


as well as data on the same religion between pairs of countries). In our robustness checks, we also add FDI taken from OECD International Direct Investment Statistics (2013).

The dataset resulting from the merging procedure covers the period from 1990 to 2015 - at five-years interval - and about 143,000 dyads (country-product) per year. To estimate the effect of migration on trade of both EU and MENA area, we split the dataset into two different sub samples leading to an estimation sample of 22,000 dyads for EU and of 15,000 for MENA, for six five-years-distant observations over the 1990-2015 period. The summary statistics are reported in Table 3 and the correlation matrix in the Appendix (Table A3).

In order to estimate the effect of migration on margins of trade by technological complexity, we used the United Nations technology classification [7] identifying four categories of technological intensity in manufacturing industries (high, medium-high, medium-low and low). However, we aggregated medium-high and medium-low classes and considered the degree of technology embodied in traded at three categories: low, medium and high technology.

In our benchmark specification we want to estimate the effect of migration on changes in both the EM and IM of trade. By using an instrumental variable approach, we will estimate the following equation through a two-stages least squares (2SLS).

$$
\text { LHS }=\beta_{\text {migrants }} \text { Migrants }_{j, i, t}+\beta_{\text {trade }} \text { trade }_{i, j, t-1}+\chi_{c, t}+\varphi_{p, t}+\varepsilon_{p, t}
$$

The LHS changes according to which margin is estimated. As said before, we consider the index of revealed comparative advantage (RCA) by Balassa (1965) that can be defined as the ratio between the shares of total exports that product $p$ represents in a country $c$ export basket and the share of the same product $p$ in global trade:

$$
R C A_{i, p, t}=\frac{\exp _{i, p, t}}{\sum_{p} \exp p_{i, p, t}} / \frac{\sum_{i} e x p_{i, p, t}}{\sum_{i} \sum_{p} \exp _{i, p, t}}
$$

where $\exp _{i, p, t}$ is the country $i$ export value of product $p$ in $t$.

The RCA, together with the product level data, allow us to construct our LHS variable at product-level for the IV specification, when the extensive margin is estimated. It will be useful also to associate the origin country of migrants to product $p$ by building a procedure of weighting that will give a weight $=1$ if migrants are coming from countries with an RCA $>1$ in product $p$ (Bahar et al., 2014; Bahar and Rapoport, 2018).

To build the extensive margin we construct, indeed, a dummy variable that equals 1 if country $i$ achieved an $R C A_{i, p, t}=1$, or more, in product $p$ at time $t$ conditional on having $R C A_{i, p, t-1}=0$ in the previous five-year period.

$$
E M_{i, p, t}=1 \text { if } R C A_{i, p, t-1}=0 \wedge R C A_{i, p, t} \geq 1
$$

It must be noticed that since we are interested in the dynamics of comparative advantages our dependent variable is equal to 1 only when the country starts exporting a given product competitively $(\mathrm{RCA} \geq 1)$. All those cases in which the RCA switches from 0 in $t-1$ to a value less than 1 at time $t$, are equal to zero. This restrictive measure of extensive margin deserves an explanation. If we built our LHS of extensive margin $\mathrm{EM}=1$ if country $i$ achieved an $R C A_{i, p, t} \geq 0$ in product $p$ at time $t$ (conditional on having $R C A_{i, p, t-1}=0$ ) would also include in the extensive margin those products which a country starts exporting but not competitively, showing a positive but very low value of exports. In our case, the idea of starting exporting means that a country becomes competitive enough to start exporting product $p$ that becomes a significant component of its export basket, so as to support the idea of a productive knowledge transfer. However, we also tested our hypotheses using a LHS variable based on a definition of extensive
EU-MENA: migration and comparative advantages 


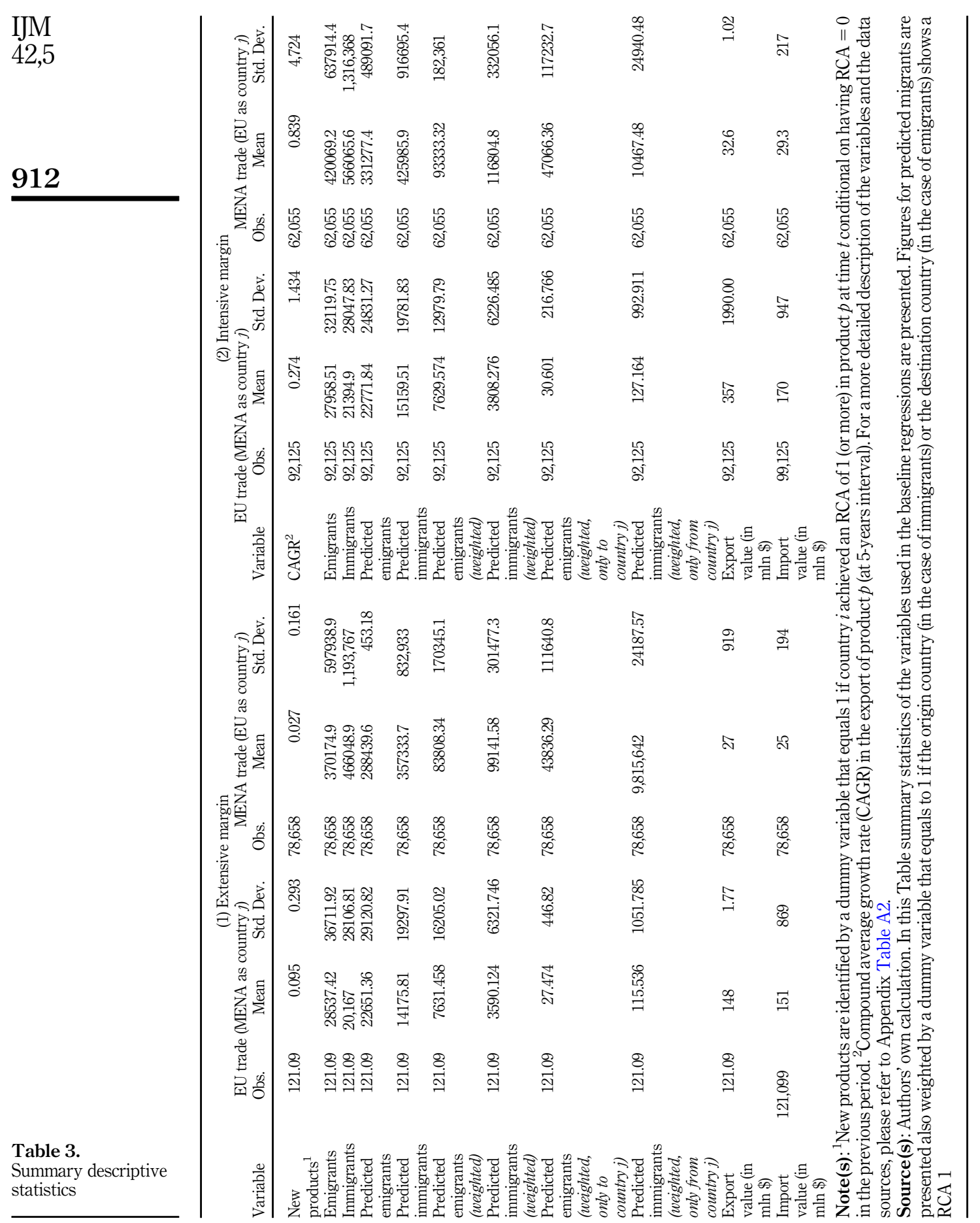


$\mathrm{EM}=1$ if country $i$ achieved an $R C A_{i, p, t}>0$ in product $p$ at time $t$ (conditional on having $R C A_{i, p, t-1}=0$ ), finding consistency in results [8].

We also estimate the effect of migration on the intensive margin. By using the compound average growth rate (CAGR) in the export of product $p$, we measure whether variations in migrants in and from countries with RCA $>1$ in a given product explain growth in the next period in the exports of the same product. Hence, IM is calculated as follows:

$$
\mathrm{IM}_{i, p, t}=\left(\frac{\operatorname{exports}_{i, p, t}}{\operatorname{exports}_{i, p, t-1}}\right)-1
$$

Our measures of EM and IM are mutually exclusive. The latter, indeed, using the growth in the export of product $p$, includes products that have already been exported by the country under consideration. In addition, the IM, measuring the increase of exports of already exported products, can be a proxy for a process of specialization that, in the long run, could lead to gain in RCA and to convergence in comparative advantages.

The independent variables migrants include, alternatively stocks of immigrants $\left(I M M_{j, i, t}\right)$ from, and of emigrants $\left(E M I_{i, j, t}\right)$ to, other countries.

Some of the major channels for knowledge diffusion across countries may include international trade and foreign direct investment (FDI) (Keller, 2004). So, in our specification we also control for the effect that those other drivers can have on knowledge flows and productivity shifts (the accumulated exports of product $p$ and value of imports of product $p$ in the previous period, FDI). All these factor flows can be highly correlated and can influence knowledge diffusion. Regarding trade, Madsen (2007) shows that trade openness positively impacts on international knowledge transmission. In addition, developing countries are more and more frequently exposed to high technology goods, particularly if they import large quantities of intermediate goods in response to the fragmentation of world production.

Moreover, when the intensive margin is estimated, we include the compound average growth rate (CAGR) of the export value in the previous period in order to control for previous growth trends.

Endogeneity in our context may arise from either omitted variables or reverse causality. In order to mitigate the possibility of an omitted variable bias, our equation also includes a vector of controls with time-varying variables that simultaneously affect the extensive and intensive margins of trade and migration figures. Migrants from a country that is exporter of a given product, indeed, might choose, based on a priori knowledge, to migrate towards countries where this sector is growing and this could induce an increase in demand, and so in trade, of the same product. More in general, changes in aggregate preferences or due to some country-specific characteristics could induce both migration and an increase in exports. We control for these potential confounders by including country-by-year $\left(\chi_{c, t}\right)$ and product-byyear $\left(\varphi_{p, t}\right)$ fixed effects. Following Hummels (1999) and Anderson and van Wincoop (2003), including country-by-year effects, we also account for all the barriers which each country faces in its trade with all trading partners, namely the multilateral trade resistance (MTR) and to control the source of bias that may arise not controlling for the time-varying component of multilateral trade resistance (i.e. the evolution of the vector of pair-wise exchange rate regimes) that is highly likely to be present.

Finally, $\varepsilon_{i t}$ is the remaining error term. Standard errors are clustered at the country level in order to correct for heteroskedasticity and serial correlation.

Since we want to check whether migrants coming from (or going to) a country that already exports a given product $p$ transfer knowledge to the destination (origin) country, and the latter starts to specialize in that product, the predicted migration stocks are weighted by a dummy variable that is equal to 1 if the RCA in a specific product is greater than one in the 
IJM

42,5

914

previous time period $\left(R C A_{c, p, t-1}=1\right)$. This also allows having on the RHS of our Equation (1) the same (spatial) dyadic (country-product) dimension of the LHS of our equation.

In Table 3, the panel (1) presents the summary statistics when the Extensive Margin is estimated, and the panel (2) when the Intensive Margin is estimated for EU and for MENA trade respectively. In our data, the unconditional probability for the average country-product of achieving RCA $>1$ (starting from having $\mathrm{RCA}=0$ in previous period) is $9.5 \%$ for $\mathrm{EU}$ and $2.7 \%$ for MENA, while the average country-product Compound Average Growth Rate (CAGR) is about 27 and $84 \%$, respectively. It is also worth mentioning that the number of emigrants is on average greater than the number of immigrants. When migrants are weighted, the figures of emigrants are on average higher than the mean of weighted immigrants as well. The reason is that we consider the mean for emigrants figures weighted by the receiving country RCA values (that correspond to the RCA values of the sending country for immigrants) and it is easy to assume that there are more migrants from poor countries (which tend to have lower RCA values) in rich countries (which tend to have higher RCA values). In our specification, when we consider the effect of migration flows between EUMENA on EU trade margins, we weight migrants by RCA values of MENA countries: the receiving countries in the case of emigrants (from EU to MENA), and the sending countries when we consider immigrants (to EU from MENA countries). Similarly, when we look at the effect of migration on the MENA countries trade margin, the weighting procedure is carried out considering the RCA of EU countries.

A legitimate concern that arises from our specification is the endogeneity of the main variable of interest: migration. To overcome this problem, we will estimate our specification (illustrated in next section) by using two stages least square (2SLS), using as instrumental variable figures from the estimation of the gravity model as instruments to provide an exogenous variation in the number of migrants, both from and to partner countries (Bahar and Rapoport, 2018). The instrument (predicted stocks of migrants), in order to be valid, should be able to explain variation in our endogenous variable (migration). By including historical and cultural proximity variable, we expect that is the case. Moreover, by including in our setting country-year fixed effects, we should control also for factors that should induce trade towards the country of origin (destination) of migrants.

\subsection{The model}

As said, for the first stage, we estimate a gravity equation (through a Poisson pseudo Maximum Likelihood (PPML)) to refine the consistency between the estimated and the actual figures of bilateral migration.

Following the work by Frankel and Romer (1999) and a rich literature adopting a similar approach (including Feyrer, 2019; Ortega and Peri, 2014; Alesina et al., 2016; Bahar and Rapoport, 2018), our methodology relies on instrumenting migration using estimates from a PPML gravity regression that computes predicted bilateral migration stocks based on common cultural and historical characteristics of the sending and receiving countries.

Thus, in the first stage we estimate a gravity equation through a (Poisson Pseudo Maximum Likelihood (PPML)) since Silva and Tenreyro $(2006,2010)$ suggest that the application of a PPML estimator in gravity settings is desirable, with respect to linear models, in settings where many zeros are present in the dependent variable, as in our case, and also to address issues related to heteroskedastic residuals.

The gravity model, shown in Equation (5), is based on cultural and historic bilateral variables between the sending and receiving countries of migrants (Frankel and Romer, 1999; Bahar and Rapoport, 2018) and we will estimate it through a PPML [9].

$$
\text { migrants }_{i, j, t}=\alpha+\beta_{1} X_{i, j}+\beta_{2} X_{i, j}{ }^{*} \gamma_{t}+\theta_{i}+\theta_{j}+\gamma_{t}+\nu_{i, j, t}
$$


The variables $X_{i, j}$ included in the estimation are dummy variables indicating: (former) colony-coloniser relationship, same coloniser, same language relationship and same religious beliefs. In order to add time dimension in our equation, and to account for differential effects of these dyadic variables across periods, we also interacted our dummies in $X_{i, j}$ with time variables (Feyrer, 2019). Therefore, this allows for time-variation in explanatory variables. This means that the predicted stocks of dyadic migrants $M_{i, j, t}$ is variable over time and can be adopted for instrumenting migration variations over time.

Our specification includes year $\left(\gamma_{t}\right)$, and receiving, and sending-country dummies $\left(\theta_{i}, \theta_{j}\right)$.

One of the conditions for the validity of the instruments is the exclusion restriction: productspecific exports must not be correlated with historical and cultural characteristics of migrants' countries. We use three precautions to avoid this and to make our results robust. First, we control for country-year fixed effect that would account for any effect that could link the cultural or historical background of the country with the comparative advantage for products. An additional precaution we take is to include in our right-hand side, as a control, trade variables (from/to the same set of countries where the migrants on the right-hand side are in/ from). This could have a double meaning: we avoid that in our instrumentation methodology there might be a component in aggregate bilateral trade which can also be explained by the same variables that explain aggregate bilateral migration, and we also could capture the effect of export-enhancing agreements based on cultural ties. Besides, although we have the same set of explanatory variables in migration and trade equations, we do not use the estimated migration values directly in the trade equation. In the trade equation, we use the weighted average of migration values where weights are $1(\mathrm{RCA} \geq 1)$ or 0 at the product level[10]. This could help the identification of the migration variable. Finally, we also implement a robustness test in which we estimate the model by using a subset of data that excludes all countries where migrants come from, i.e. to all those countries with a propensity to send or receive migrants (with same coloniser, same language, same religion and former colony-coloniser relationship).

\section{Results}

Results for the baseline model are shown in Table 4, for MENA-EU migration flows pro trade effects, disentangling the whole effect also by technology groups.

In column 1-4 we do report the results of the analysis run with OLS where we use migration directly without instrumenting it. The results are remarkably similar to those we obtain by the IV shown in column 5-8. Both models for the overall sample shows that the spillover effects for EU countries impact only through the channel of immigration and occur via increases in the IM. Emigrants conversely have a negative but weakly significant effect on the EM.

Comparing the results for the three technology product categories (columns 9-20), the increase in the IM concerns especially medium tech products but also involves the two other product categories. This is a reasonable result considering North trade as a result of migration from South as in our case. Migrants from MENA are mostly composed of medium level of skilled workers, able to impact on trade mainly in medium tech sectors and less in lowand high-tech sectors. High-tech firms are likely to be comparatively highly productive and to rely on highly skilled partnerships in a globalized market. In such sectors, the information content is not necessarily more accessible to immigrants or emigrants as it is likely not to be so much culture-related but rather related to highly complex and product-specific knowledge.

Overall, there is evidence of a positive effect of immigration in promoting exports. However, although inducing a pro trade effect, migrants from the MENA region may not carry with them enough information and knowledge to induce a change in the EU comparative advantages in new products, and hence in the EM.

Our estimations show that a country with a $10 \%$ increase in the stock of immigrants from MENA countries (that export a product $p$ and with an RCA $>1$ ) is associated with an increase 
IJM
42,5

916

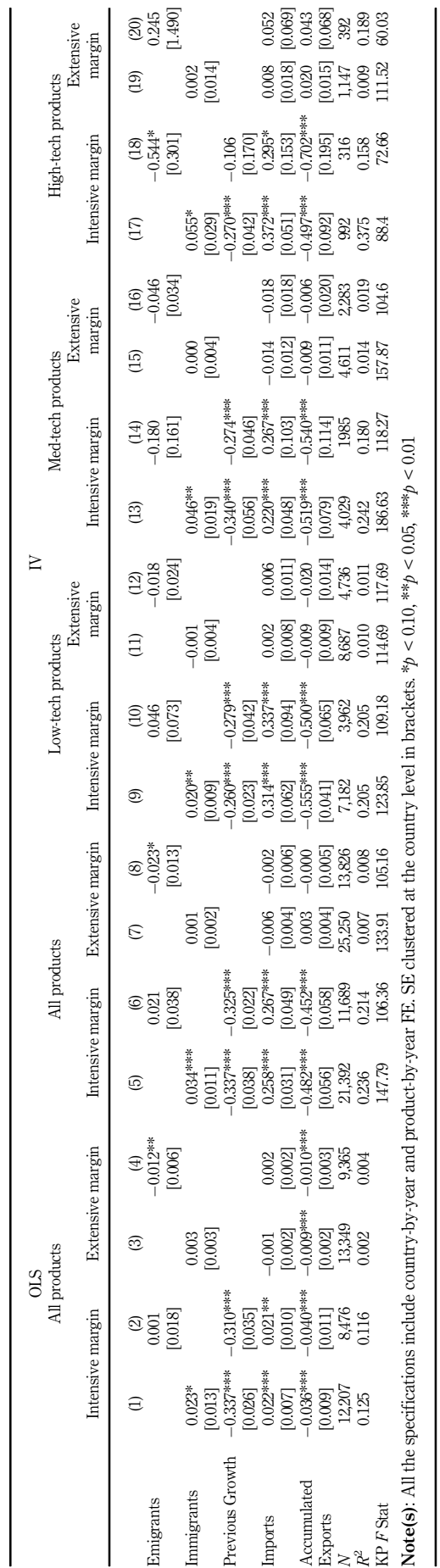

Table 4.

Effects on Margins of trade of European countries - (Emigrants (Immigrants) to (from) MENA) - Benchmark estimates 
in the export growth rate of $0.34 \%$ points. This percentage increases a little bit for mediumtech products (0.46) and is lower for products with low level of technology (0.2). It must be noticed that an increase of $0.34 \%$ points could be approximated to an increase in trade, for the average European country, of almost 2 million of US\$ in the total trade of a given product $p$. These results suggest that immigrants coming from MENA countries are a significant driver of knowledge for European trade.

Looking at the MENA trade we find evidence of immigrant pro trade effects on the intensive margin only as far as low tech products are concerned combined with a negative impact on the extensive margin (Table 5). These results suggest low skilled migrant flows from $\mathrm{EU}$ which in case of return migrants might be related to the type of occupation which immigrant can get in EU as typically concentrated in low skilled sectors.

Regarding the economic dimension of the results for MENA country, we find that a $10 \%$ increase in the stock of immigrants from EU countries (that export a product $p$ and with an $\mathrm{RCA}>1$ ) is associated with up to $0.33 \%$ increase in the likelihood that the receiving country will export higher share of low tech products in the next five years.

Our results are in line with previous studies on EU-MENA trade [11] which have found as in our case a robust correlation between stocks of immigrants and exports. Compared with the literature on the export immigration link, we find a relatively larger effect of immigrants, in line with the results of other IV estimates (Bratti et al., 2014). The estimated elasticities of export to immigrants in many studies range between 0.07 and 0.40 although most of the estimates are in the interval 0.1-0.2 (Peri and Requena-Silvente, 2010).

As for the other variables of the model, we expected a positive coefficient for accumulated exports since there is a considerable literature showing how trade is a driver of knowledge diffusion (Coe et al., 2009) rather than being mere shipping of goods (Frankel and Romer, 1999). Yet, stronger export links are also a driver of specialization which might counteract the learning effect of trade while imports are a vehicle of knowledge transmission which may spur new export. Hence, we are not surprised to find significant and positive coefficient on imports while a negative coefficient for accumulated exports. This confirms that knowledge flows are obtained in inflows rather than in outflows of goods. Moreover, the fact that imports have no explanatory power when the extensive margin is estimated, means that the more a product is imported from a country, the less this product will emerge in the export basket of that country, as evidence of trade specialization.

The lagged CAGR, the growth-related control we use when the intensive margin is estimated, has the expected sign correlating negatively with future growth, consistently with convergence effects.

About the weak effects on extensive margin which emerge from our estimates, it needs to be emphasized that it is more difficult to achieve a change in EM (fixed costs, etc.). Moreover, the product classification we use (SITC 4 digit), although quite detailed, is still somewhat a broad classification, and some of the EM might be disguised under the IM margin [12].

We further compared our analysis with EU and MENA trade and migration from (and to) other areas (e.g. East Asian developing countries for EU and other developed areas for MENA).

We observe that EU immigration from East Asia leads to impoverishment of trade, as if a brain drain or a substitute effect would be at work. MENA trade and migration from (and to) other developed areas leads to a stronger increase of trade of MENA, especially of the IM of trade, with respect to the trade creation realized with the EU area (see tab. A.4 and A.5).

\section{Robustness checks and extensions}

\subsection{International flows of capital, goods and labour}

A further step of our analysis is to consider the correlation between international flows of capital, goods and labour [13]. In our specification of Equation (1), we already considered
EU-MENA: migration and comparative advantages 
IJM
42,5

918

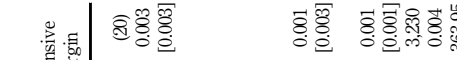

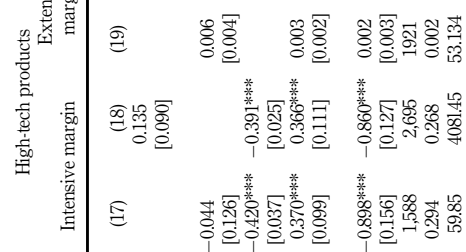



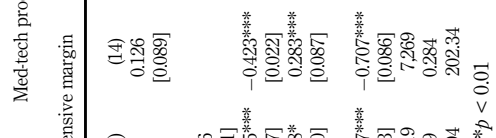

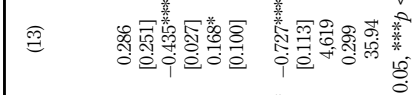

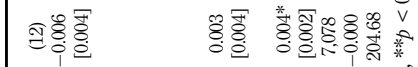

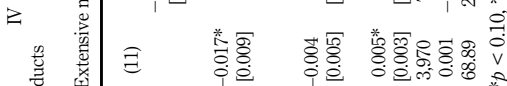

$$
\begin{aligned}
& \text { 吾 }
\end{aligned}
$$

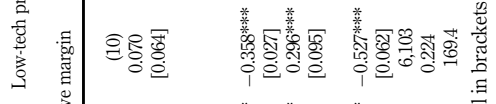

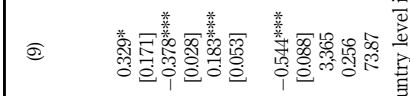

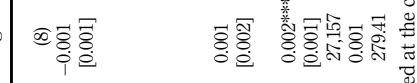

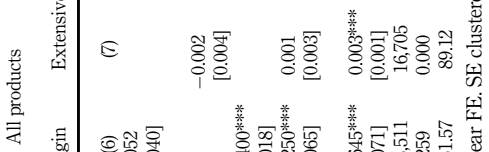

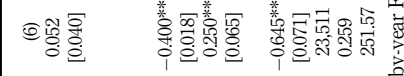

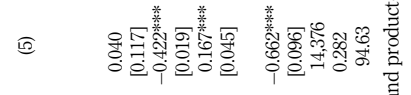

$$
\begin{aligned}
& \text { † } \\
& \text { त }
\end{aligned}
$$

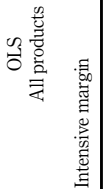

Effects on Margins of trade of MENA

countries - (Emigrants

(Immigrants) to (from)

EU) - Benchmark

estimates 
trade variables in order to capture the trade dimension of this transfer. In this section, we also consider the sum of the stock of FDI (inflows plus outflows) on the RHS of our equation [14] weighted by the RCA of the origin/destination country. We include FDI controls since we know that these international flows can be channels for technological transfers between nations and because they are strongly correlated with migration flows. Foreign-invested firms can directly increase the quality of exports by producing higher quality products but may also foster the production of higher technology goods in domestic firms (Javorcik, 2004). As the data are on OECD countries and cover up to 2013, they shrink a little the country [15] and time coverage of our dataset. The estimation results presented in Tables 6 and 7 are about the 1995-2010 period.

Our results are in line with previous ones. The positive and significant effect on the IM of European countries is confirmed for immigrants from MENA. When we include FDI in our estimation, while they seem to have no explanatory power when the IM is estimated, the effect of FDI on the growth of newly exported products (EM) is positive (and significant). This result seems to confirm that one of the main obstacles in the emergence of new products (and industries) are the fixed costs associated to starting new industries, that in the case of IM have already been paid while for EM are not. There is higher chance to afford these costs for the multinationals.

Including FDI as control variable in trade creation for MENA we observe that the elasticity of the IM of trade to immigration in low tech product decreases, while it turns significant in medium tech products.

\subsection{Business networks and knowledge spillovers}

We must consider that the relationship linking "trade with trade" [16], through knowledge, is a sort of black box. There could be several aspects influencing the impact of migration on trade, indeed. One of the concerns about the validity of our exercise could be the effect of overseas diaspora networks that could lower role played by networks in reducing information, communication and set up cost, i.e. the transaction costs, increasing the bilateral component of exports between locations (Gould, 1994; Rauch and Trindade, 2002; Aubry et al., 2017; Bahar and Rapoport, 2018).

Thus, in the attempt to isolate the effects of knowledge spillovers we have tried to refine the analysis in this section, by focusing on the effects of immigrants and emigrants on trade (of both EU and MENA) with third countries excluding trade with the partners of origin and destination area of migration. Hence, we reconstructed our dependent variables excluding exports to countries where emigrants go to, or immigrants come from. This will exclude that our dependent variable product-level exports are explained by overseas diaspora business networks which reduce transaction costs, enhancing bilateral exports.

The results are presented in Table 8 for EU countries. These checks confirm the baseline model results for the EU trade, i.e. the positive effect of immigrants from MENA to EU on the IM of trade, for low tech products. However, two new unexpected results emerge: first, we get an immigrants' positive impact on trade not only via intensive margin but also via extensive margin in high tech products and furthermore, we find a negative impact on the EM in low tech ones. These results might be interpreted not as due to a transfer of knowledge by immigrants. They seem rather suggest a mechanism of reallocation of production according to which an increase in immigrant leads to increase the export intensity in low tech goods (higher elasticity of IM to immigrants in low tech products) but at the same time they also allow to move the specialisation towards new more advanced sectors (significant coefficient of EM and IM in high tech products).

In Table 9 we check MENA countries trade elasticity to EU migration excluding exports to EU (and including the FDI among the control variables). Here we observe two main novel 
IJM
42,5

920

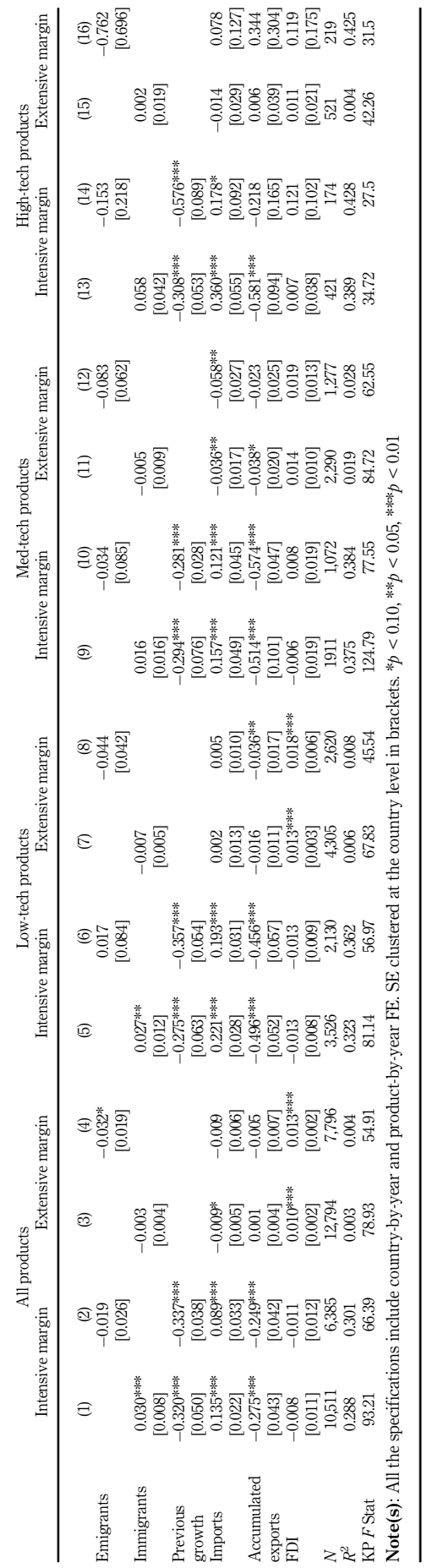

Table 6.

Effects on Margins of trade of European countries including the FDI - (Emigrants (Immigrants) to (from) MENA) 


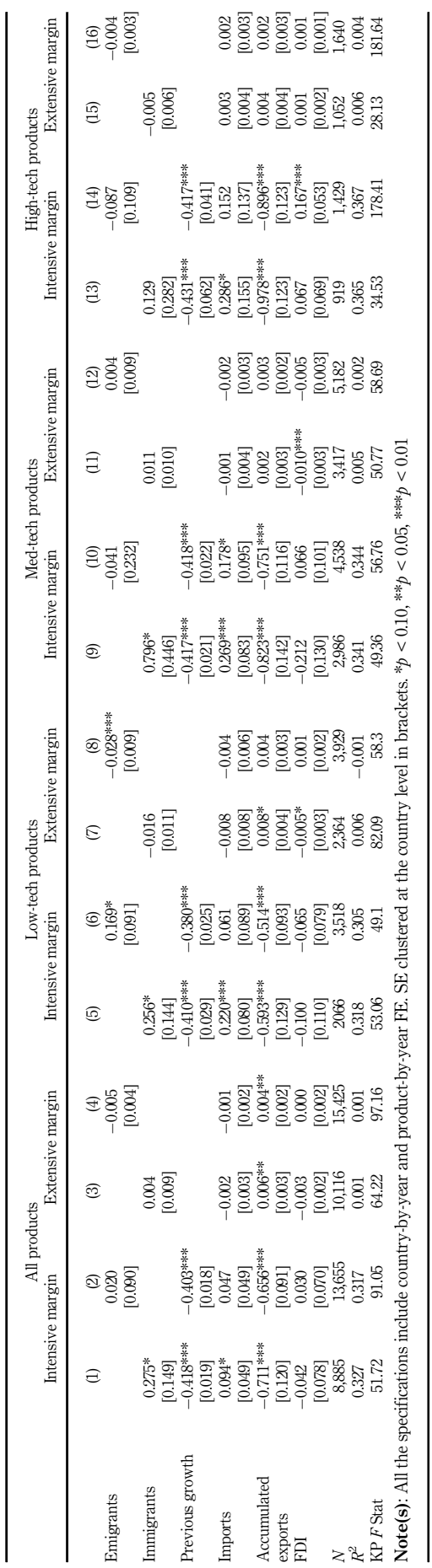

EU-MENA: migration and comparative advantages

921

Table 7 . Effects on Margins of trade of MENA countries including the FDI - (Emigrants (Immigrants) to (from) $\mathrm{EU})$ 
IJM

922

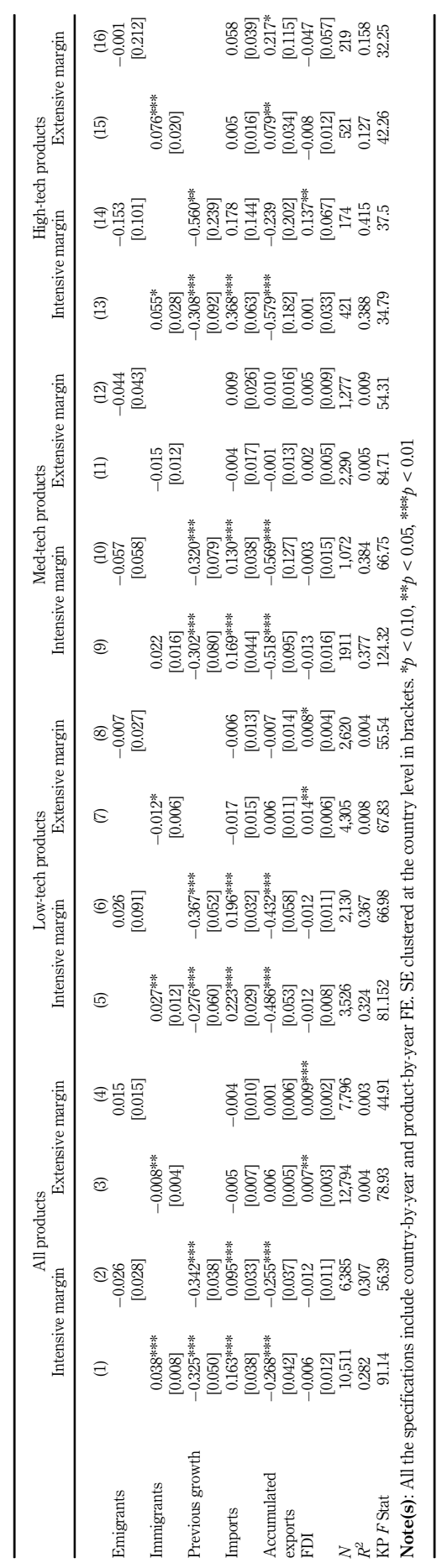

Table 8.

Effects on Margins of trade of European countries including the FDI - (Emigrants (Immigrants) to (from) MENA)Dependent variables computed excluding exports to those countries where migrants are in or from 


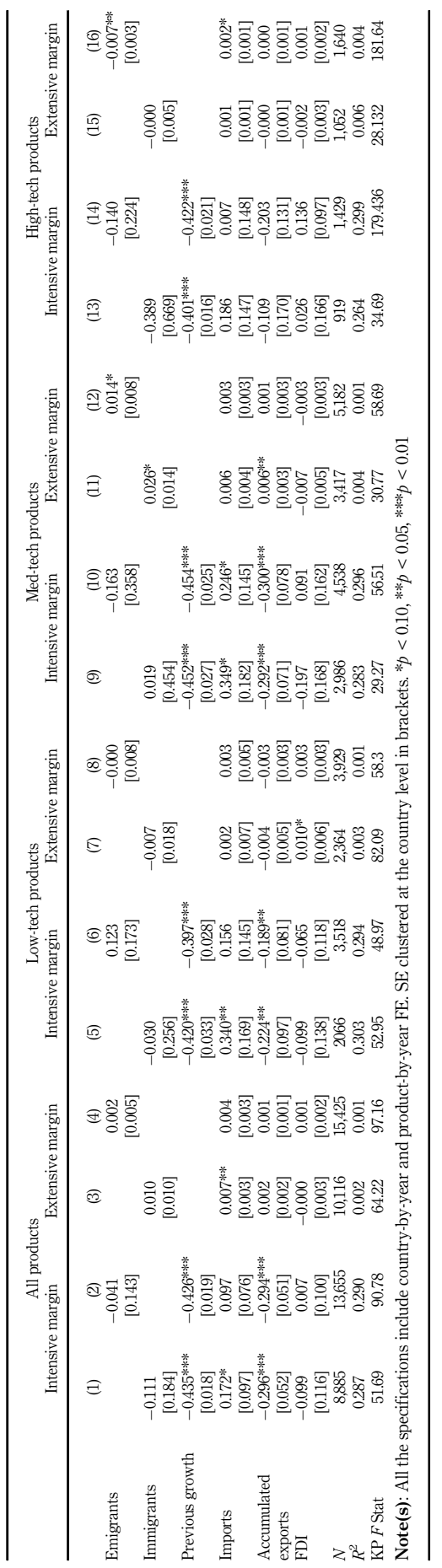

EU-MENA: migration and comparative advantages

923

Table 9. Effects on Margins of trade of MENA countries including the FDI - (Emigrants (Immigrants) to (from) EU)Dependent variables computed excluding exports to those countries where migrants are in or from 
IJM

42,5

results: first, now we observe an impact on the extensive trade margin in medium tech products occurring both via immigration and emigration. Hence, this dependent variable being a more accurate proxy for knowledge transfer reveal the positive impact of migration on MENA comparative advantages. However, there is a negative impact of emigrants on the EM in high tech products, which might suggest a possible brain drain.

\section{Conclusions}

In our study the impact of migration flows on the country's trade margins suggests a productive knowledge transfer between MENA and EU with different effects for immigration and emigration. We find a positive effect for immigrants, while the results for the outflows of emigrants appear not robustly significant. These results are quite in line with our expectations: immigrants are vehicle of knowledge transferred through more direct interactions, while the productive knowledge across outflows of migrants should happen through return migration, or through links and communication between emigrants and their co-nationals back home.

If we look at the margins of trade, in our baseline results, knowledge diffusion seems to have a stronger impact on the IM with different patterns at sectoral level. As regards migrants to EU from MENA, their trade-promoting effect on IM controlling for FDI occurs in low tech goods. Moreover, when we look at migrants from EU to the MENA region, a promoting effect on the IM of trade of this region controlling for FDI appears in low and in medium tech ones.

We check whether these results hold to a robustness check based on repeating the analysis excluding exports to those countries where migrants are in or from to exclude network and preferences effects. Positive immigration effects on the IM found both for MENA and for EU appear robust to this testing. However, a relevant impact on the EM appears in both regions. Excluding trade with EU countries which are source and destination of migration we observe that there is a significant impact on the EM of MENA countries in medium tech goods. Excluding trade with MENA, a positive impact on the EM for EU countries appears in high tech products.

We further compared our analysis with EU and MENA trade and migration from (and to) other areas (e.g. East Asian developing countries for EU and other developed areas for MENA) [17]. We observe that EU immigration from East Asia leads to impoverishment of trade. Conversely, MENA trade and migration from (and to) other developed areas leads to a stronger increase of trade of MENA, especially of the IM of trade, with respect to the trade creation realised with the EU area.

Identifying specifically the right mechanisms, or the precise type of knowledge, that could be transferred through movements of people is not straightforward. Migrants could transfer knowledge becoming entrepreneurs (e.g. Ortega and Peri, 2014; Kerr and Kerr, 2020) or through innovation (e.g. patents) (e.g. Coe et al., 2009; Kerr and Kerr, 2018). However, as Keller (2004) in his review on the different drivers of knowledge diffusion points out, knowledge by nature is intangible and it is difficult to measure it directly and to identify the channel of its diffusion, so one of the more widely used indirect measure of knowledge diffusion is through its effects (e.g. higher productivity).

Part of our future research, indeed, is to consider other dimensions, such as the labour market status of migrants in terms of sectors of occupation in both home and host country and level of skills. It is reasonable to suppose, indeed, that if immigrants (emigrants) end up working in the sector in which the country of origin (destination) has comparative advantage, it is more likely for them to channel the information to the destination (origin) country about this comparative advantage. Besides, we would like to measure the knowledge transmission channel by considering the skill level of migrants following previous studies (Beenstock et al., 2015; Giovannetti and Lanati, 2017; Giovannetti et al., 2019). Both improvements can only be 
realized by adopting other data sources as in our data from UN we only have international migrant stock by age, sex and origin.

However, our results provide first evidence that productive knowledge can be transferred via migration flows, leading to a convergence in trade specialization.

Our analysis is also useful to understand the channels through which knowledge can be widespread giving some guidance for future policy designs. Knowledge, through the channel of migration, could induce a process of convergence in specialization among countries on a global scale. Our results point to build appropriate policies that could give migrants the right tools to fully transfer the knowledge they have embodied. Policies investing in education, appropriate training for the right skills, would help the natural and spontaneous process of knowledge diffusion.

The findings of our analysis provide also useful inputs for improving the policy making process in host countries, especially in the field of migration policy, with the aim of enhancing trade and knowledge transfer. Interdependencies between migration and trade policies pointed out by the results of our investigation are meaningful, indeed, for the EU-MENA region integration process.

\section{Notes}

1. MENA includes Algeria, Bahrain, Djibouti, Egypt, Iran, Iraq, Jordan, Kuwait, Yemen, United Arab Emirates, Lebanon, Libya, Morocco, Oman, Palestinian Territory, Qatar, Saudi Arabia, Sudan, Syria, Tunisia.

2. This vision has been originally suggested by Arrow (1969), who argued that the transmission of tacit or non-codifiable knowledge relies on human minds rather than on written words.

3. In the "network approach", the basic idea is that international networks of people, created by larger stocks of immigrants in a given country, can help in reducing information costs (such as start-up and commercialization fixed costs) that firms have to pay to enter a new market improving both export participation and intensity of exports.

4. Blanes and Martín-Montaner (2006) for Spain; Tadesse and White (2011) for Italy; Briant et al. (2009) for France; Peridy (2012) for France; Artal-Tur et al., (2012) for Italy, Spain and Portugal. See also Artal-Tur and Pallardó-López (2012).

5. We refer to "immigration" in a country as the stock of residents in that country who hold a foreign citizenship not considering people that have acquired local nationality. It also only refers to formally residing people, neglecting undocumented immigrants. Moreover, our data do not allow to include undocumented immigrants and economically active and inactive migrants. So, from the data at our disposal, it is not deductible immigrants' occupation and if they actively contribute to trade (e.g. if they are entrepreneurs or intermediaries).

6. For historical data (1990-2000), the data are from The Center of International Data of Robert Feenstra. For more recent data (2005-2015) they are from the UN COMTRADE with corrections implemented by Bahar et al. (2014) for the bilateral trade data.

7. The UN technology classification is built on Lall (2000). We consider, the manufactures excluding natural resource-based products (e.g. petroleum products).

8. These results are presented in Appendix.

9. The results of the estimation of the gravity model are presented in Appendix Table A1.

10. In all of our IV estimations, to tackle concerns regarding weak instrumentation, we report the Kleibergen-Paap $F$-statistic. The critical value of the Kleibergen-Paap $F$ statistic, calculated by Stock and Yogo (2005), is 16.38 in our case.

11. See Foad (2010), Peridy (2012), Artal-Tur et al. (2012), Cagatay et al. (2014), Giovannetti and Lanati (2017) and Giovannetti et al. (2019). 
IJM

42,5

\section{6}

12. For example, let us assume that there are two products, SITC 11111 and 11112 . These two are classified under SITC 1111. If a country starts to export SITC 11112 as a result of migration, we would measure it as a growth in exports (IM), not as new export. If we might use, SITC 5- or 6-digit products then a change in EM is more likely. However, our dataset would become too difficult to manage and the elaborations would be very slow.

13. The positive correlation between capital labour and goods flows is confirmed also by the results we present in the upper panel of Table A5 in the Appendix. All the correlations of the (log-transformed) flows across countries are positive and above 0.5 .

14. In this version of our work, the FDI are from OECD International Direct Investment Statistics (2013). We consider this extension as a robustness check, but we are now extending the country and year coverage of our dataset to include FDI in our main estimation, i.e. Equation (5).

15. The data by the OECD International Direct Investment Statistics do not proved information about bilateral FDI stocks on following countries: Bulgaria, Croatia, Cyprus, Latvia, Lithuania, Luxembourg, Malta, Romania.

16. This expression refers to the fact that our benchmark specification connects the size of the trade in the country of destination/origin of the migrants (extensive or intensive margin) with the size of the trade, vice versa, in the country of origin/destination of the migrants (since with the weighting we weight them for those who have an RCA $>1$ ). So, we link trade (RCA in a product) with trade (EM and IM).

17. Results in Appendix Table A2.

\section{References}

Agrawal, A., Kapur, D., McHale, J. and Oettl, A. (2011), "Brain drain or brain bank? The impact of skilled emigration on poor country innovation", Journal of Urban Economics, Vol. 69 No. 1, pp. 43-55.

Aldieri, L., Kotsemir, M. and Vinci, C.P. (2020), "The role of labour migration inflows on R\&D and innovation activity: evidence from Russian regions", International Journal of Manpower, Vol. 22 No. 4, pp. 437-468.

Aleksynska, M. and Peri, G. (2014), "Isolating the network effect of immigrants on trade", The World Economy, Vol. 37 No. 3, pp. 434-455.

Alesina, A., Harnoss, J. and Rapoport, H. (2016), "Birthplace diversity and economic prosperity", Journal of Economic Growth, Vol. 21 No. 2, pp. 101-38.

Andersen, T.B. and Dalgaard, C.J. (2011), "Flows of people, flows of ideas, and the inequality of nations", Journal of Economic Growth, Vol. 16 No. 1, pp. 1-32, doi: 10.1007/s10887-011-9060-7.

Anderson, J. and van Wincoop, E. (2003), "Gravity with gravitas: a solution to the border puzzle”, The American Economic Review, Vol. 93 No. 1, pp. 170-192.

Arrow, K.J. (1969), "Classificatory notes on the production and transmission of technological knowledge", The American Economic Review, Vol. 59 No. 2, pp. 29-35.

Artal-Tur, A., Pallardó-López, V. and Requena-Silvente, F. (2012), "The trade-enhancing effect of immigration networks: new evidence on the role of geographic proximity", Economics Letters, Elsevier, Vol. 116 No. 3, pp. 554-557.

Artal-Tur, A., Bacaria-Colom, J., Cagatay, S. and Pallardó-López, V. (2014), "The determinants of migrants' remittance inflows in the MENA region: a macroeconomic approach", in The SocioEconomic Impact of Migration Flows, Springer, Cham, pp. 97-120.

Aubry, A., Rapoport, H. and Reshef, A. (2017), Migration, FDI and the Margins of Trade, Mimeo, Paris School of Economics, Paris.

Bahar, D. and Rapoport, H. (2018), "Migration, knowledge diffusion and the comparative advantage of nations", The Economic Journal, Vol. 128, pp. F273-F305, doi: 10.1111/ecoj.12450. 
Bahar, D., Hausmann, R. and Hidalgo, C.A. (2014), "Neighbors and the evolution of the comparative advantage of nations: evidence of international knowledge diffusion?", Journal of International Economics, Elsevier, Vol. 92 No. 1, pp. 111-123.

Balassa, B. (1965), "Trade liberalisation and revealed comparative advantage", The Manchester School, Vol. 33 No. 2, pp. 99-123.

Beenstock, M., Ramos, R. and Suriñach, J. (2015), "Migration, human capital and social capital: lessons for the EU neighboring countries", International Journal of Manpower, Vol. 36 No. 4, pp. 434-440.

Beine, M., Docquier, F. and Rapoport, H. (2001), "Brain drain and economic growth: theory and evidence", Journal of Development Economics, Vol. 64 No. 1, pp. 275-289.

Blanes, J.V. and Martín-Montaner, J. (2006), "Migration flows and intra-industry trade adjustments", WeltwirtschaftlichesArchiv (Review of World Economics), Vol. 142 No. 3, pp. 567-584.

Bratti, M., De Benedictis, L. and Santoni, G. (2014), "On the pro-trade effects of immigrants”, Review of World Economics (Weltwirtschaftliches Archiv), Vol. 150 No. 3, pp. 557-594.

Bottazzi, L. and Peri, G. (2003), "Innovation and spillovers in regions: evidence from European patent data”, European Economic Review, Vol. 47 No. 4, pp. 687-710.

Briant, A., Combes, P.P. and Lafourcade, M. (2009), "Product complexity, quality of institutions and the pro-trade effect of immigrants", Working paper 2009/06, Paris School of Economics, Paris.

Çağatay, S., Değirmen, S., Genç, M., Koska, O.A., Lucke, B. and Saygın, P.Ö. (2014), "Analyzing the immigration-induced changes in product diversity and trade patterns: the case of the EUMediterranean-Eastern Europe Zone", in The Socio-Economic Impact of Migration Flows, Springer, Cham, pp. 53-86.

Coe, D.T. and Helpman, E. (1995), "International R\&D spillovers", European Economic Review, Vol. 39 No. 5, pp. 859-887, doi: 10.1016/0014-2921(94)00100-E.

Coe, D.T., Helpman, E. and Hoffmaister, A.W. (2009), "International R\&D spillovers and institutions", European Economic Review, Vol. 53 No. 7, pp. 723-741.

Disdier, A.C. and Mayer, T. (2007), "Je t’aime, moi non plus: bilateral opinions and international trade", European Journal of Political Economy, Vol. 23 No. 4, pp. 1140-1159.

Docquier, F. and Rapoport, H. (2012), "Globalization, brain drain, and development", Journal of Economic Literature, Vol. 50 No. 3, pp. 681-730.

Feyrer, J. (2019), "Trade and income-exploiting time series in geography", American Economic Journal: Applied Economics, Vol. 11 No. 4, pp. 1-35.

Foad, H. (2010), "Assimilation and trade between the Middle East, Europe, and North America", Review of Middle East Economics and Finance, Vol. 6 No. 2, pp. 74-92, doi: 10.2202/14753693.1298 .

Frankel, J. and Romer, D. (1999), “Does trade cause growth?”, The American Economic Review, Vol. 89 No. 3, pp. 379-99.

Giovannetti, G. and Lanati, M. (2017), "Do high-skill immigrants trigger high-quality trade?”, The World Economy, Vol. 40 No. 7, pp. 1345-1380, doi: 10.1111/twec.12431.

Giovannetti, G., Lanati, M. and Venturini, A. (2019), "Migration and trade in the Mediterranean”, in Mediterranean Migration and the Labour Markets, Policies for Growth and Social Development, Routledge, London, pp. 224-237.

Gould, D.M. (1994), "Immigrant links to the home country: empirical implications for U.S. bilateral trade flows", The Review of Economics and Statistics, Vol. 76 No. 2, pp. 302-316.

Head, K. and Mayer, T. (2014), "Gravity equations: toolkit, Cookbook, Workhorse”, in Gopinath, G., Helpman, E. and Rogoff, K.S. (Eds), Handbook of International Economics, Elsevier, Amsterdam, Vol. 4. 
IJM

42,5

928

Head, K., Mayer, T. and Ries, J. (2010), “The erosion of colonial trade linkages after independence", Journal of International Economics, Vol. 81 No. 1, pp. 1-14.

Head, K. and Ries, J. (1998), "Immigration and trade creation: econometric evidence from Canada", Canadian Journal of Economics, Vol. 31 No. 1, pp. 47-62.

Hummels, D.L. (1999), Toward a Geography of Trade Costs, Available at SSRN 160533.

Jaffe, A.B., Trajtenberg, M. and Henderson, R. (1993), "Geographic localization of knowledge spillovers as evidenced by patent citations", Quarterly Journal of Economics, Vol. 108 No. 3, pp. 577-598.

Javorcik, B. (2004), "Does Foreign Direct Investment increase the productivity of domestic firms? In search of spillovers through backward linkages", The American Economic Review, Vol. 94 No. 3, pp. 605-608.

Keller, W. (2004), "International technology diffusion”, Journal of Economic Literature, Vol. 42, pp. $752-82$.

Kerr, W.R. (2008), "Ethnic scientific communities and international technology diffusion", The Review of Economics and Statistics, Vol. 90 No. 3, pp. 518-37.

Kerr, S.P. and Kerr, W.R. (2018), "Global collaborativepatents", The Economic Journal, Vol. 128 No. 612, pp. F235-F272.

Kerr, S.P. and Kerr, W. (2020), "Immigrant entrepreneurship in America: evidence from the survey of business owners 2007 and 2012", Research Policy, Vol. 49 No. 3, Article 103918.

Lall, S. (2000), "The technological structure and performance of developing country manufactured exports, 1985-98", Oxford Development Studies, Vol. 28 No. 3, pp. 337-369.

Lissoni, F. (2018), "International migration and innovation diffusion: an eclectic survey", Regional Studies, Vol. 52 No. 5, pp. 702-714.

Lodigiani, E. (2008), "Diaspora externalities and technology diffusion”, Economie Internationale, Vol. 115 No. 3, pp. 43-64.

Madsen, J.B. (2007), “Technology spillover through trade and TFP convergence: 135 years of evidence for the OECD countries", Journal of International Economics, Vol. 72, pp. 464-480.

Mayr, K. and Peri, G. (2009), "Brain drain and brain return: theory and application to Eastern-Western Europe", The BE Journal of Economic Analysis and Policy, Vol. 9 No. 1, pp. 1-52.

Miguélez, E. (2018), "Inventor Diasporas and the internationalization of technology", The World Bank Economic Review, Vol. 32 No. 1, pp. 41-63, doi: 10.1093/wber/lhw013.

Naghavi, A. and Strozzi, C. (2015), "Intellectual property rights, diasporas, and domestic innovation", Journal of International Economics, Vol. 96 No. 1, pp. 150-161.

OECD (2013), OECD International Direct Investment Statistics, OECD.

Ortega, F. and Peri, G. (2014), "Openness and income: the roles of trade and migration”, Journal of International Economics, Vol. 92 No. 2, pp. 231-51.

Parsons, C.R. and Winters, L.A. (2014), "International migration, trade and aid: a survey", in Lucas, R.E.B. (Ed.), International Handbook on Migration and Economic Development, Edward Elgar Publishing, Cheltenham.

Pastore, F., Ferragina, A.M. and Giovannetti, G. (2009), "A tale of parallel integration processes: a gravity analysis of EU trade with Mediterranean and central and eastern European countries", Review of Middle East Economics and Finance, Vol. 5 No. 2, pp. 21-44.

Péridy (2012), "Recent migration patterns from MENA countries to the EU: a quantitative assessment and policy implications", in FEMISE Project n. 34-01, The Trade Creation Effect of Immigrants: Characterising Socioeconomic Opportunities Arising from Linkages Between People's and Goods' Flows Inside the Mena Region. 
Peri, G. and Requena-Silvente, F. (2010), "The trade creation effect of immigrants: evidence from the remarkable case of Spain", Canadian Journal of Economics/Revue canadienned'économique, Vol. 43 No. 4, pp. 1433-1459.

Rapoport, H. (2016), "Migration and globalization: what's in it for developingcountries?", International Journal of Manpower, Vol. 37 No. 7, pp. 1209-1226.

EU-MENA: migration and comparative advantages

Rauch, J.E. (1999), "Networks versus markets in international trade", Journal of International Economics, Vol. 48, pp. 7-35.

Rauch, J.E. (2001) "Business and social networks in international trade", Journal of Economic Literature, Vol. XXXIX, pp. 1177-1203.

Rauch, J.E. and Trinidade, V. (2002), "Ethnic Chinese networks in international trade", The Review of Economics and Statistics, Vol. 84, pp. 116-130.

Silva, J.S. and Tenreyro, S. (2006), "The log of gravity”, The Review of Economics and Statistics, Vol. 88 No. 4, pp. 641-658.

Silva, J.S. and Tenreyro, S. (2010), "On the existence of the maximum likelihood estimates in Poisson regression”, Economics Letters, Vol. 107 No. 2, pp. 310-312.

Stock, J.H. and Yogo, M. (2005), "Testing for weak instruments in linear IV regression, Working paper version: NBER Technical Working Paper No. 284", in Andrews, D.W.K. and Stock, J.H. (Eds), Identification and Inference for Econometric Models: Essays in Honor of Thomas Rothenberg, Cambridge University Press, Cambridge.

Tadesse, B. and White, R. (2011), "Emigrant effects on trade: Re-examining the immigrant-trade link from the home country perspective”, Eastern Economic Journal, Vol. 37 No. 2, pp. 281-302.

United Nations (2017), "Trends in international migrant stock: the 2017 revision", Department of Economic and Social Affairs, Population Division.

Valette, J. (2018), "Do migrants transfer productive knowledge back to their origin countries?", Journal of Development Studies, Vol. 54 No. 9, pp. 1637-1656.

Wagner, D., Head, K. and Ries, J. (2002), "Immigration and the trade of provinces", Scottish Journal of Political Economy, Vol. 49, pp. 507-525.

White, R. (2007), "Immigrant-trade links, transplanted home bias and network effects", Applied Economics, Vol. 39 No. 7, pp. 839-852.

\section{Corresponding author}

Anna Maria Ferragina can be contacted at: aferragina@unisa.it 
$\mathrm{IJM}$
42,5

\section{Appendix}

Gravity Models Results- estimation to predict migration stocks (PPML)

(Coeff)

Total stocks

930

Colony
Common coloniser

Common religion beliefs

Common language

Colony\#1995

Colony\#2000

Colony\#2005

Colony\#2010

Colony\#2015

Common coloniser\#1995

Common coloniser\#2000

Common coloniser\#2005

Common coloniser\#2010

Common coloniser\#2015

Com_religion\#1995

Com_religion\#2000

Com_religion\#2005

Com_religion\#2010

Com_religion\#2015

Com_language\#1995

Com_language $\# 2000$

Com_language\#2005

Com_language \#2010

Table A1.

Com_language\#2015

Gravity models resultsestimation to predict migration

Constant

$N$

$$
\begin{gathered}
2.341^{* * *} \\
1.502^{* * * *} \\
0.910^{* *} \\
0.773^{* * * *} \\
-0.098^{* *} \\
-0.220^{* * *} \\
-0.308^{* * *} \\
-0.439^{* * * *} \\
-0.442^{* * *} \\
-0.066 \\
-0.179^{* *} \\
-0.285^{* *} \\
-0.287 \\
-0.336^{*} \\
-0.255^{*} \\
-0.218^{*} \\
-0.260 \\
-0.084 \\
0.003 \\
0.030 \\
0.015 \\
0.111 \\
0.130 \\
0.124 \\
10.664 * * * \\
58,832
\end{gathered}
$$

Note(s): Standard errors in brackets; ${ }^{*} p<0.10,{ }^{* *} p<0.05,{ }^{* * *} p<0.01$ 
Variables

Migration

Immigrants

Emigrants

Trade and FDI

Extensive

margin

Intensive margin

Imports

Accumulated

exports

FDI

Gravity model variables

Log (Migrantsijt) Biltaral migration stocks from $i$ residing in

Colony

Common

coloniser

Common religion

beliefs

Common

language
The sum of the stock of FDI (inflows plus outflows)

Stock of immigrants in country $i$ from country $j$ in year $t$

Stock of emigrants from country $i$ to country $j$ in year $t$

A dummy variable that equals 1 if country $i$ achieved an RCA of 1 (or more) in product $p$ at time $t$ conditional on having $\mathrm{RCA}=0$ in the previous period the export of product $p$ (at 5-years interval) Value of imports (including product $p$ ) The accumulated exports of products (different from $p$ )

$$
j \text { at time } t
$$

Dummy equal to 1 if country $i$ and $j$ share a colonial past and 0 otherwise Dummy indicating if two countries have had a common colonizer after 1945

Index of Religious proximity (Disdier and Mayer, 2007)

Dummy equal to 1 if country $i$ and $j$ share a common official or primary language and 0 otherwise
Definition and source

Data are from United Nations "Trends in International Migrant Stock: The 2017 revision”, Department of Economic and Social Affairs. Population Division (2017). Data were obtained from population censuses. In most of the cases, in most countries or areas, international migrants have been equated with the foreign-born population (whenever this information is available). In countries lacking data on place of birth, information on the country of citizenship of those enumerated was available. When both information was available, they have been compared effectively equating

Product data of EU-27 countries and of 20 MENA countries with more than 200 countries. For 1990-2000 the data are from The Center of International Data of Robert Feenstra. For more recent data (2005-2015) they are from the UN COMTRADE with corrections implemented by Bahar et al. (2014) for the bilateral trade data. Products classified according to the Standard Industry Trade Classification (SITC) (Rev. 2) with a 4-digit level of detail amounting to more than 700 single products

Bilateral FDI 1990-2012 stocks from OECD International Direct Investment Statistics (2013)

United Nations "Trends in International Migrant Stock: The 2017 revision", Department of Economic and Social Affairs. Population Division (2017) CEPII Gravity Dataset (Head et al., 2010; Head and Mayer, 2014)
EU-MENA: migration and comparative advantages
Table A2.

Variables description and main data sources 


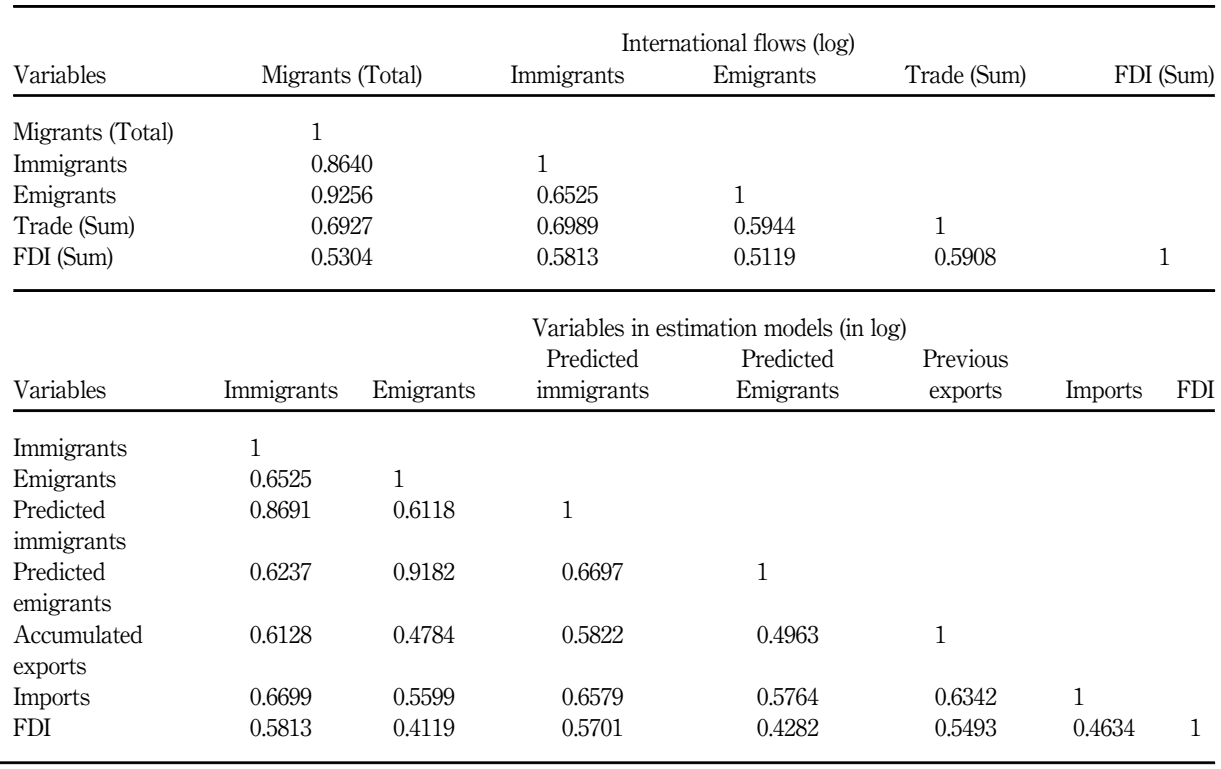

Table A3.

Correlation matrices

932

A2 - Testing pro-trade effects of different countries of origin with respect to EU and MENA In this section, we focus on the migration dimension of developed and non-developed trade partners. We concentrate on two specific regions. For EU trade we consider the trade migration elasticity towards developing East Asia. For MENA region, as partner of equal level of development as EU, we focus on developed countries.

For EU (MENA) trade the question is whether and how MENA (EU) differs from other developing (developed) regions in terms of what role migration plays.

In Table A4 we display the results for EU trade considering East Asia developing countries as a source and destination of migration flows. The picture we observe reveal a strong negative impact of both immigrants and emigrants on both the EM and the IM of trade. The brain drain overcoming network and knowledge transfer impact might be at the origin of this result. The negative effect observed for immigrants on the intensive margin of trade in mid and high-tech goods suggests that there may be an additional channel at play. By keeping production costs low thanks to the immigrants' lower bargaining power, firms may have a way to avoid costly investments in $R \& D$ or relocations abroad.

In Table A5 the same exercise carried out for MENA reveals, on the contrary, a much higher benefit from migration flows which MENA countries obtain from other developed countries. The impact is concentrated on the immigration flows and, on the IM, but the novelty is that it occurs in advanced and medium tech sectors and not only in low tech products.

These results hint a very different composition of migrant's flows directed to EU with respect to those directed to other developed areas such as USA and Canada. 
EU-MENA: migration and comparative advantages

933

Table A4. Effects on Margins of trade of EU countries (Emigrants (Immigrants) to (from) East Asian Developing countries) 
IJM

934

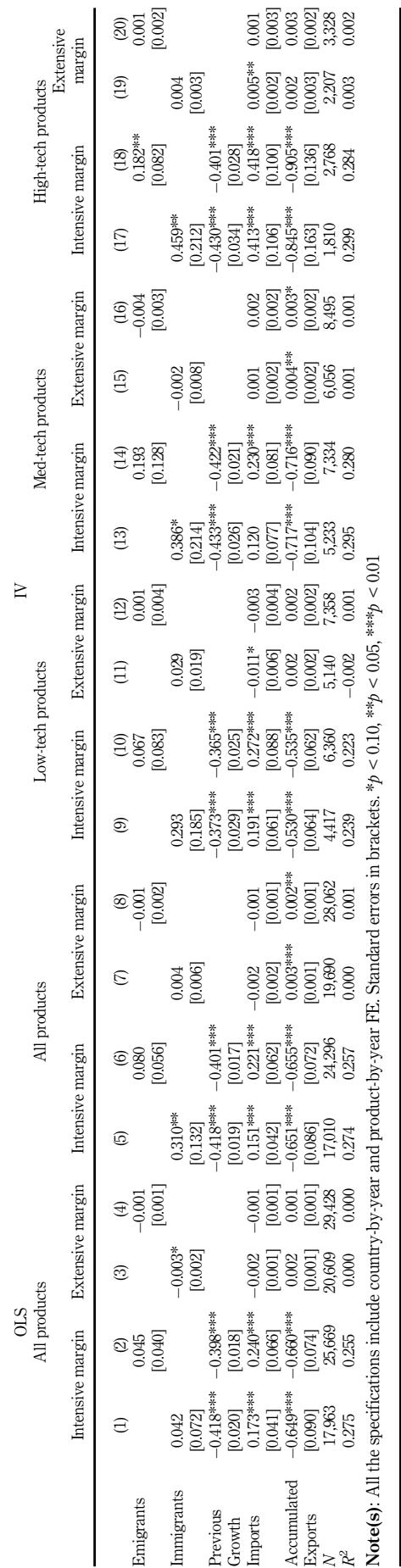

Table A5.

Effects on Margins of trade of MENA

countries - (Emigrants (Immigrants) to (from) Developed Countries) 